\title{
Electroacupuncture Enhances Preproenkephalin mRNA Expression in Rostral Ventrolateral Medulla of Rats
}

\author{
Min Li ${ }^{*}$, Stephanie C. Tjen-A-Looi, and John C. Longhurst \\ Department of Medicine and Susan Samueli Center of Integrative Medicine, College of Medicine, \\ University of California, Irvine, CA 92697-4075
}

\begin{abstract}
Electroacupuncture (EA) causes prolonged suppression of reflex elevations in blood pressure for at least 60 minutes in anesthetized preparations. Thus, EA can modify sympathetic outflow and elevated blood pressure through actions in a number of hind brain regions, including the rostral ventrolateral medulla (rVLM). Since our previous data show that the opioid system plays a role in EA-related prolonged inhibition of presympathetic neuronal activity in the rVLM, we postulated that EA increases preproenkephalin (PPE) mRNA in this region, possibly for prolonged periods of time. Under $\alpha$-chloralose anesthesia, rats received EA (1-2 mA, $2 \mathrm{~Hz}, 0.5 \mathrm{~ms})$ at P5-P6 acupoints (overlying median nerves) or sham (needle placement without electrical stimulation) for $30 \mathrm{~min}$. PPE mRNA in the rVLM also was evaluated in control rats that received surgery but no EA or sham treatment. $20 \mathrm{~min}, 1.5 \mathrm{~h}$ or $4 \mathrm{~h}$ following EA or sham treatment, PPE mRNA in the rVLM was analyzed by reverse transcription and quantitative real-time PCR. Relative ratios of PPE mRNA levels (normalized with $18 \mathrm{~s}$ house keeping gene) were increased $1.5 \mathrm{~h}$ after EA stimulation (7.77 \pm $1.39, \mathrm{n}=6)$ relative to sham $(2.84 \pm 0.37, \mathrm{n}=5)$ but were unchanged both $20 \mathrm{~min}$ and $4 \mathrm{~h}$ after EA, compared to the sham or surgery groups at the same time points. Thus, 30 min of EA transiently stimulates the production of enkephalin in a region of the brain that importantly regulates sympathetic outflow suggesting that even a single brief acupuncture treatment can increase the expression of this modulatory neuropeptide.
\end{abstract}

\section{Keywords}

electroacupuncture; rostral ventrolateral medulla; opioids; enkephalin; blood pressure

\section{Introduction}

Acupuncture or electroacupuncture (EA) increasingly is being accepted as a viable therapy for treating a range of heart diseases, including mild to moderate hypertension [1]. EA reduces elevated blood pressure by stimulating somatic sensory nerves that then provide inhibitory input to cardiovascular centers in a number of regions in the hypothalamus, midbrain and brain stem, including the rostral ventrolateral medulla (rVLM) [18,19,24,27]. The rVLM is important because it is the source of many presympathetic bulbospinal neurons that project to the

\footnotetext{
(c) 2010 Elsevier Ireland Ltd. All rights reserved.

*Corresponding author. Tel: +1 949824 8161; fax: +1 949824 2200. mli4@uci.edu .

Publisher's Disclaimer: This is a PDF file of an unedited manuscript that has been accepted for publication. As a service to our customers we are providing this early version of the manuscript. The manuscript will undergo copyediting, typesetting, and review of the resulting proof before it is published in its final citable form. Please note that during the production process errors may be discovered which could affect the content, and all legal disclaimers that apply to the journal pertain.
} 
intermediolateral columns of the thoracic spinal cord, the site of origin of sympathetic preganglionic neurons $[10,25,26]$.

A distinguishing aspect of acupuncture is its ability to cause prolonged modulation of elevated blood pressure and cardiovascular excitatory reflex responses. The prolonged influence of acupuncture in hypertension has been reported in both clinical [14] and experimental studies [4,16,20,28-30]. For example, the blood pressure lowering effect of EA in hypertensive patients can last four weeks after complete cessation of treatment [14]. Also, a ****long-lasting cardiovascular modulatory response to acupuncture has been documented in unanesthetized spontaneously hypertensive for 5-12 h [28,29] as well as in anesthetized reflex-induced hypertensive rats for at least $60 \mathrm{~min}[4,16,30]$ and in certain cases for up to $290 \mathrm{~min}$ [20]. Blood pressure elevation in many of these models is a response to enhanced activity of the sympathetic nervous system, which is modulated by the EA $[4,16,30]$.

Our laboratory has shown that stimulation of P5-P6 acupoints increases the discharge of bulbospinal neurons in the rVLM [21,25,27] Premotor sympathetic cardiovascular neurons in the rVLM receive convergent input from the splanchnic nerve (innervating gastrointestinal organs) and the median nerve, which is activated during stimulation of P5-P6 acupoints [3, 15]. EA at P5-P6 attenuates the excitatory responses of rVLM neurons to input from visceral afferents, in part, through an opioid mechanism, since naloxone (a nonspecific opioid receptor antagonist) microinjected into this brain stem region impairs the cardiovascular inhibition induced by EA [25]. Furthermore, our laboratory has identified the order of potency of opioid receptor involvement during EA inhibition in the rVLM as $\delta=\mu>>\kappa$, suggesting that enkephalins, $\beta$-endorphin and endomorphin, but not dynorphin, likely serve as the important neuromodulators of this process [17].

Enkephalin has high affinity for $\delta$-opioid receptors. Consistent with our electrophysiological data, we have demonstrated that c-Fos expression, a marker for neural activation by EA, is increased in the rVLM following median nerve activation during stimulation of P5-P6 acupoints [8]. Moreover, using confocal microscopy we have demonstrated that following 30 min of EA, neurons double-labeled with c-Fos and enkephalin in the rVLM are increased [8]. A long-loop pathway linking the ventral hypothalamus and midbrain to the rVLM likely contributes, in part, to the prolonged EA-cardiovascular response [18]. Our previous studies also have suggested that long-term neural inhibition by EA could result from increased synthesis of neurotransmitters in the rVLM, especially enkephalin, which, unlike $\beta$-endorphin [9], is synthesized in this region of the brain stem [8,24]. Thus, an increased synthesis of modulatory neurotransmitters in the rVLM could contribute to the prolonged action of EA on sympathetic outflow and ultimately on blood pressure. However, previous studies have not determined if EA activates the gene expression of opioid precursors, like preproenkephalin, in this region of the medulla. Therefore, in the present study, the preproenkephalin mRNA in the rVLM was determined $20 \mathrm{~min}, 1.5$ and $4 \mathrm{~h}$ following $30 \mathrm{~min}$ of a single application of low frequency, low intensity EA, the type of somatic nerve stimulation that has been shown to be effective in lowering elevated blood pressure for 60-90 min [24]. We hypothesized that EA increases preproenkephalin mRNA for at least $1.5 \mathrm{~h}$ in the rVLM of normotensive anesthetized rats after a single 30 min application of acupuncture. Part of this study has been presented as a preliminary report [12].

\section{Materials and methods}

Experimental preparations and protocols were reviewed and approved by the Institutional Animal Care and Use Committee of the University of California, Irvine. The study conformed to the American Physiological Society's Guiding Principles for Research Involving Animals and Human Beings. Male Sprague-Dawley rats (400 to $500 \mathrm{~g}$ ) after overnight fast were 
anesthetized initially with a mixture of ketamine/xylazine $(100 / 10 \mathrm{mg} / \mathrm{kg}$, i.m.) and subsequently were maintained with $\alpha$-chloralose $(50-60 \mathrm{mg} / \mathrm{kg}$, i.v.). Additional doses of $\alpha$ chloralose (25-30 mg/kg, i.v.) were given as necessary to maintain an adequate level of anesthesia, as assessed by the lack of response to noxious toe pinch, a respiratory pattern that followed the respirator, as well as a stable blood pressure and heart rate. A femoral artery cannula was inserted and attached to a pressure transducer (Statham P 23 ID, Gould) for measuring arterial blood pressure. The femoral vein was cannulated for administration of sodium bicarbonate (to correct arterial $\mathrm{pH}$ ) and $\alpha$-chloralose. Gallamine triethiodide ( $4 \mathrm{mg} / \mathrm{kg}$ ) was administered intravenously to avoid any muscle movement during stimulation of somatic nerves. After paralysis was completed, supplemental $\alpha$-chloralose was administrated on a regular basis. The trachea was intubated and artificial respiration was maintained with a ventilator (model 661, Harvard Apparatus). Heart rate was derived from the pulsatile blood pressure signal. Arterial blood gases and $\mathrm{pH}$ were measured periodically with a blood-gas analyzer (ABL5, Radiometer America) and were kept within normal physiological limits $\left(\mathrm{PcO}_{2} 30-40\right.$ Torr and $\mathrm{Po}_{2}>100$ Torr) by adjusting ventilatory rate or volume and enriching the inspired $\mathrm{O}_{2}$ supply. Arterial $\mathrm{pH}$ was maintained between 7.35-7.40 by infusion of a solution of $8 \%$ sodium bicarbonate. Body temperature was kept at $35-37^{\circ} \mathrm{C}$ with a heating pad.

Following surgical preparation, four acupuncture needles, two on each side bilaterally, were inserted at P5-P6 acupoints (over the median nerve) and connected to an electrical stimulator to perform low frequency, low intensity EA ( $2 \mathrm{~Hz}, 2-4 \mathrm{~mA}, 0.5$-ms duration) for $30 \mathrm{~min}$. Correct positioning of the needles at the acupoint was confirmed by observing slight repetitive paw twitches during stimulation, indicating stimulation of motor fibers in the median nerve [3]. We have found previously that this level of stimulation leads to significant modulation of excitatory cardiovascular reflex responses that is not dependent on the muscle contraction since it remains following muscle paralysis [19].

Anesthetized rats were killed by intravenous $\mathrm{KCl}$, the brain was quickly removed and stored in RNA Later solution (Ambion) to prevent RNA degradation. After overnight storage, the brain stem was removed and frozen immediately on dry ice. A punch biopsy was made from ventral side by using an 18-gauge needle stub (inner diameter of $1 \mathrm{~mm}$ ) connected to a $5 \mathrm{ml}$ syringe. The location of the biopsy was medial to the lateral edge of the pyramid tract and dorsal to the rostral edge of the trapzoid body (Fig 1A). This region overlaps with areas in the rVLM where we have recorded premotor neuronal activity that is inhibited by EA [4]. Left or right rVLM tissue samples within $1 \mathrm{~mm}$ of the ventral surface were collected. We found no difference in preproenkephalin mRNA levels between the left and right rVLM (data not shown) and therefore pooled the data.

After punching, the brain stems were fixed in 10\% paraformadehyde ( $\mathrm{pH} 7.4$ ) for at least 2 days. They were sliced with a microtome cryostat at a thickness of $40 \mu \mathrm{m}$. The missing areas in the brain stem were checked histologically to confirm that they were in the rVLM (Fig 1B).

Tissue samples were homogenized in a glass tissue grinder (DUALL 20, Kontes Glass Co.) by using $800 \mu \mathrm{l}$ Trizol reagent (Life Technologies). Total RNA was extracted using the manufacturer's protocol. The RNA was dissolved in $10 \mu \mathrm{l}$ nuclease-free water and the concentration and purity of RNA determined spectrophotometerically using a Nanodrop ND-1000 spectrophotometer (NanoDrop Technologies). One hundred nanograms of total RNA were transcribed using SuperScript II RT (Invitrogen) and a mixture of oligo (dT) (100 ng/ reaction) and random primers (200 ng/reaction) according to the manufacture's protocol. Realtime quantitative PCR was performed with an Opticon 4 (Bio-Rad) using the SYBR green realtime master mix (Bio-Rad). The following primer sequences were used: preproenkephalin, forward ( $5^{\prime}$-tgc ctt ctt tca aaa tct gg-3'), reverse ( $5^{\prime}$-ggg gta aag ctc atc cat ct- $\left.3^{\prime}\right)$; 18 s, forward ( $5^{\prime}$-cgg aca gga ttg aca gat tg- $\left.3^{\prime}\right)$, reverse (5'-acg cca ctt gtc cct cta ag- $\left.3^{\prime}\right)$. The primer sequences 
were designed to span intron-exon boundaries to avoid amplification of genomic DNA. The sizes of the PCR products were: preproenkephalin-191 bp, 18s-185 bp. The PCR program was $95^{\circ} \mathrm{C} 10 \mathrm{~min},\left(95^{\circ} \mathrm{C} 10 \mathrm{sec}, 59^{\circ} \mathrm{C} 45 \mathrm{~s}\right) \times 50$ cycles followed by the melting curve analysis $\left(55^{\circ}\right.$ $\mathrm{C}-90^{\circ} \mathrm{C}$ ) to verify the product specificity. To create a standard curve for each gene of interest, rat cDNA corresponding to the region analyzed was amplified with the same specific primers. A solution containing the corresponding amplification fragment was analyzed with a spectrophotometer and the molecular number calculated. A standard curve then was generated by analysis of the serial dilutions of fragment solutions $\left(10^{2}-10^{7}\right.$ copies/ $\left.\mu l\right)$. For each sample the copy number of both preproenkephalin and 18 s housekeeping gene were extrapolated from their respective standard curves. The value of preproenkephalin mRNA expression was normalized with the $18 \mathrm{~s}$ copy number and expressed in arbitrary units. Reproducibility of results was determined by performing triplicate measurements of each cDNA aliquot.

\section{Experimental procedures}

\section{Experimental protocol 1}

EA, anesthetized rats: Following surgical preparation, four acupuncture needles were inserted bilaterally (2/side) at the P5-P6 acupoints (over median nerve) and connected to an electrical stimulator to perform EA ( $2 \mathrm{~Hz}, 2-4 \mathrm{~mA}, 0.5-\mathrm{ms}$ duration) for $30 \mathrm{~min}$. Correct positioning of the needles at the acupoints was confirmed by observing slight repetitive paw twitches during stimulation, indicating stimulation of motor fibers in the median nerve [3].

\section{Experimental protocol 2}

Sham acupuncture in anesthetized rats: The same treatment protocol detailed above was used, except needles were inserted but not stimulated electrically.

\section{Experimental protocol 3}

Baseline anesthesia group: Rats were instrumented as detailed above but without insertion of needles as with EA or sham treatment.

The brain stems were harvested 20 min, 1.5 or $4 \mathrm{~h}$ following treatment of acupuncture in all protocols.

All values are presented as means \pm SEM. We used the Kolmogorov-Smirnoff test to determine if the data were normally distributed. Comparisons between two groups were analyzed statistically with the Student's $t$-test, and values were considered to be significantly different when $\mathrm{P}<0.05$. All statistical calculations were performed with a statistical software package (SigmaStat, Version 3.0).

\section{Results}

There were no significant changes in blood pressure $(110 \pm 9 \mathrm{mmHg})$ or heart rate $(400 \pm 25$ bpm) before, during and after EA stimulation (Fig.2). Changes of blood pressure and heart rate did not appear in the sham or baseline groups either.

Preproenkephalin mRNA was increased $1.5 \mathrm{~h}$ after EA, relative to baseline, while preproenkephalin in the sham group was unaltered (Fig.3). Conversely, PPE mRNA levels were similar $20 \mathrm{~min}$ after EA in the EA and sham groups. PPE mRNA expression in EA and sham groups $4 \mathrm{hr}$ after treatment were not different. The baseline PPE mRNA levels at $20 \mathrm{~min}$, $1.5 \mathrm{~h}$ and $4 \mathrm{~h}$ without treatment likewise were similar. Thus, the relative ratios of PPE mRNA levels were increased $1.5 \mathrm{~h}$ after treatment with EA but not at the $20 \mathrm{~min}$ or 4 hour time points (Fig.3). As shown in Fig 1.B, all samples were found to be located within the region of the rVLM as defined by the atlas of Paxinos and Watson [22], and in the level I region of PPE 
mRNA staining of the rVLM [23]. Specifically, they were located $1.0-2.0 \mathrm{~mm}$ rostral to the obex, 1.6-2.6 $\mathrm{mm}$ lateral to the midline, within $1 \mathrm{~mm}$ to the ventral surface [22].

\section{Discussion}

The present study, for the first time, provides quantitative data on the expression of preproenkephalin mRNA in the rVLM over a 4 hour period of following acupuncture stimulation using real-time PCR. The main findings of this study were: Preproenkephalin mRNA in the rVLM was increased $1.5 \mathrm{~h}$ after EA relative to baseline, while preproenkephalin in the sham and baseline group was unaltered. Conversely, preproenkephalin mRNA was unchanged both 20 min and $4 \mathrm{~h}$ after EA, compared with sham or surgery group at the same time points.

Acupuncture is distinguished from other somatosensory autonomic responses by the relative specificity of acupoints in treating a number of clinical conditions and by the prolonged nature of its influence. In this regard, our laboratory has demonstrated point specific EA regulation of cardiovascular sympathoexcitatory responses related to the extent of afferent stimulation and convergent input to cardiovascular neurons in the rVLM [25]. One well-recognized set of acupoints, Jianshi and Neiguan, P5-P6 (located along the pericardial meridian), positioned directly over the median nerve on the wrist, when stimulated has been shown experimentally to be able to effectively treat hypertension and symptomatic coronary heart disease [3]. Our studies also have provided a frame-work to understand the mechanism of EA's action on cardiovascular function. Long-loop pathways contributing to prolonged inhibition of blood pressure by EA involve the arcuate nucleus (ARC) in the ventral hypothalamus, the ventrolateral periaqueductal gray (vlPAG) in the midbrain, and the nucleus raphe pallidus (NRP) and rVLM in the brain stem [18,21,24,27]. These nuclei and pathways underlie acupuncture's influence on sympathetic outflow. Thus EA at P5-P6 involves stimulation of the median nerves, which activates the ARC and vlPAG both of which ultimately inhibit premotor sympathoexcitatory neurons in the rVLM and blood pressure increases induced by visceral afferent stimulation. Our previous physiological studies have shown that inhibitory neuromodulators, including the opioid system, play a major role in the prolonged inhibition of neuronal activity in the rVLM [24]. In the present study, which focused on the rVLM, we concentrated on the precursor for enkephalin rather than $\beta$-endorphin because our earlier data indicated that while enkephalins are produced in the rVLM, endorphins are synthesized in the arcuate nucleus and then transported by a long pathway to the rVLM [18].

Because the EA inhibitory effect in anesthetized reflex-induced hypertensive animals can last for between 60 and $290 \mathrm{~min}[16,20]$ and because our previous study has shown that $1.5 \mathrm{~h}$ following $30 \mathrm{~min}$ of EA activated nuclei are present in perikarya of rVLM neurons containing enkephalin peptides [8], we chose time points of $20 \mathrm{~min}, 1.5$ and $4 \mathrm{~h}$ following EA to study the influence of EA on preproenkephalin gene expression. Consistent with our laboratory's previous anatomical study [8], we noted that preproenkephalin mRNA levels in the rVLM were increased $1.5 \mathrm{~h}$ after EA. However, preproenkephalin mRNA was not altered $20 \mathrm{~min}$ or $4 \mathrm{~h}$ following EA compared to control values, thus demonstrating that with a single application of acupuncture for $30 \mathrm{~min}$ there is transient activation of preproenkephalin gene expression in the rVLM.

A previous study [6] using a semi-quantitative technique, Northern blotting, to assess preproenkephalin mRNA level in the whole brain less cerebral cortex and cerebellum, has shown that 30 min of EA $(2-15 \mathrm{~Hz})$ in the awake Wistar rats induces an increase of preproenkephalin mRNA, which begins at $4 \mathrm{~h}$, and peaked at $48 \mathrm{~h}$ after the termination of EA. The same research group using in situ hybridization [7] also showed that $2 \mathrm{~Hz}$ EA for $30 \mathrm{~min}$ in awake Wistar rats increases mRNA expression of preproenkephalin in paragigantocellular 
nucleus, which is adjacent to rVLM, compared with a naïve group which did not receive treatment. Given the large differences in techniques and areas of the brain that were studied, it is difficult to compare these earlier studies with the present investigation. However, they do suggest that enkephalins may be increased in the brain following acupuncture and form an important backdrop for our investigation.

As noted earlier, the rVLM serves a crucial role in regulating premotor sympathetic outflow to the spinal cord and ultimately the cardiovascular system [5]. Preproenkephalin mRNA is present in bulbospinal rVLM neurons with putative sympathoexcitatory and vasomotor functions, including approximately $20 \%$ of $\mathrm{C} 1$ and most of non-C1 neurons [23]. The presence of increased preproenkephalin mRNA does not necessarily mean that the cells make more enkephalin peptide. However, the regulation of enkephalin peptide synthesis is mainly at the mRNA level [2] and certainly increased preproenkephalin mRNA suggests that there is the potential for more peptide to be produced and thus ultimately to be available for release following electroacupuncture [17].

Even though our previous studies have shown that the opioid system is activated by EA [17], the situations under which enkephalin peptide are likely to be released for the modulation of inputs to sympathetic preganglionic neurons are not fully known [11]. Acupuncture does not significantly influence blood pressure in normotensive humans [13] or animals [8], consistent with our present observations. An interesting finding was that preproenkephalin mRNA was increased without concomitant changes in blood pressure in normal rats, indicating that EA activation of somatic nerves is capable of inducing preproenkephalin mRNA synthesis in the absence of any blood pressure changes and secondary reflex effects from other regions like the arterial baroreceptors. Furthermore, these data suggest that the extent and duration of increase in preproenkephalin during and after a single $30 \mathrm{~min}$ period of acupuncture is not sufficient to alter resting sympathetic outflow and ultimately blood pressure.

We were surprised to note that preproenkephalin mRNA was not altered 20 min post EA when the inhibitory effect of EA in reflex-induced hypertension in anesthetized animals is most profound [17]. Rather, the increase in preproenkephalin occurred later, 90 min following EA. These data suggest that neurons in the rVLM release existing enkephalin peptide during acute hypertension and that the new preproenkephalin simply helps to recharge the cellular content of this opioid peptide.

In summary, the present study provides the first quantitative evidence that EA applied at the P5-P6 EA can induce preproenkephalin mRNA expression $1.5 \mathrm{~h}$ after termination of the procedure. This study complements our previous anatomical, electrophysiological and pharmacological findings that EA evokes activation of enkephalinergic neurons in the rVLM, which contribute to reductions in sympathetic outflow and blood pressure when it is elevated.

\section{Acknowledgments}

We are sincerely thankful to Jesse Ho, Alvin Nguyen, Kimberley Nguyen and Emily Ling for their technical assistance. This study was supported by NIH HL-63313 and HL-072125.

\section{Reference List}

[1]. Andersson S, Lundeberg T. Acupuncture - from empiricism to science: functional background to acupuncture effects in pain and disease. Med. Hypotheses 1995;45:271-281. [PubMed: 8569551]

[2]. Borsook D, Hyman ES. Proenkephalin gene regulation in the neuroendocrine hypothalamus: a model of gen regulation in the CNS. Am. J. Physiol 1995;269:E393-E408. [PubMed: 7573416] 
[3]. Chao DM, Shen LL, Tjen-A-Looi SC, Pitsillides KF, Li P, Longhurst JC. Naloxone reverses inhibitory effect of electroacupuncture on sympathetic cardiovascular reflex responses. Am. J. Physiol 1999;276:H2127-H2134. [PubMed: 10362696]

[4]. Crisostomo M, Li P, Tjen-A-Looi SC, Longhurst JC. Nociceptin in rVLM mediates electroacupuncture inhibition of cardiovascular reflex excitatory response in rats. J. Appl. Physiol 2005;98:2056-2063. [PubMed: 15649868]

[5]. Dampney RAL. Functional organization of central pathways regulating the cardiovascular system. Physiol. Rev 1994;74:323-364. [PubMed: 8171117]

[6]. Guo H-F, Cui X, Hou YP, Tian JH, Wang XM, Han JS. C-Fos proteins are not involved in the activation of preproenkephalin gene expression in rat brain by peripheral electric stimulation (electroacupuncture). Neurosci. Lett 1996;207:163-166. [PubMed: 8728475]

[7]. Guo H-F, Tian JH, Wang XM, Fang Y, Hou YP, Han JS. Brain substrates activated by electroacupuncture of different frequencies (I): comparative study on the expression of oncogene c-fos and genes coding for three opioid peptides. Mol. Brain Res 1996;43:157-166. [PubMed: 9037529]

[8]. Guo Z-L, Moazzami A, Longhurst JC. Electroacupuncture induces c-Fos expression in the rostral ventrolateral medulla and periaqueductal gray in cats: relation to opioid containing neurons. Brain Res 2004;1030:103-115. [PubMed: 15567342]

[9]. Guo Z-L, Longhurst JC. Expression of c-Fos in arcuate nucleus induced by electroacupuncture: Relations to neurons containing opioids and glutamate. Brain Res 2007;1166:65-76. [PubMed: 17662967]

[10]. Guyenet, PG. Role of ventral medulla oblongata in blood pressure regulation. In: Loewy, AD.; Spyer, KM., editors. Central Regulation of Autonomic Functions. Oxford University Press; 1990. p. $145-167$.

[11]. Leng G, Ludwig M. Neurotransmitters and peptides: whispered secrets and public announcements. J. Physiol 2008;586:5625-5632. [PubMed: 18845614]

[12]. Li M, Tjen-A-Looi SC, Longhurst JC. Electroacupuncture enhances preproenkephalin mRNA expression in rostral ventrolateral medulla of rats. FASEB J 2009;23:958.

[13]. Li P, Ayannusi O, Reed C, Longhurst JC. Inhibitory effect of electroacupuncture (EA) on the pressor response induced by exercise stress. Clin. Auton. Res 2004;14:182-188. [PubMed: 15241647]

[14]. Li P, Longhurst JC. Long-lasting inhibitory effect of EA on blood pressure in patients with mild to moderate hypertension. Society for neuroscience 2007;37 417.15/CCC26.

[15]. Li P, Pitsillides KF, Rendig S, Pan H-L, Longhurst JC. Reversal of reflex-induced myocardial ischemia by median nerve stimulation: a feline model of electroacupuncture. Circulation 1998;97:1186-1194. [PubMed: 9537345]

[16]. Li P, Rowshan K, Crisostomo M, Tjen-A-Looi SC, Longhurst JC. Effect of electroacupuncture on pressor reflex during gastric distention. Am. J. Physiol 2002;283:R1335-R1345.

[17]. Li P, Tjen-A-Looi SC, Longhurst JC. Rostral ventrolateral medullary opioid receptor subtypes in the inhibitory effect of electroacupuncture on reflex autonomic response in cats. Auton. Neurosci 2001;89:38-47. [PubMed: 11474645]

[18]. Li P, Tjen-A-Looi SC, Guo Z-L, Fu L-W, Longhurst JC. Long-loop pathways in cardiovascular electroacupuncture responses. J. Appl. Physiol 2009;106:620-630. [PubMed: 19074569]

[19]. Li P, Tjen-A-Looi SC, Longhurst JC. Excitatory projections from arcuate nucleus to ventrolateral periaqueductal gray in electroacupuncture inhibition of cardiovascular reflexes. Am. J. Physiol 2006;209:H2535-H2542.

[20]. Lovick TA, Li P, Schenberg LC. Modulation of the cardiovascular defence response by low frequency stimulation of a deep somatic nerve in rats. J. Auton. Nerv. Syst 1995;50:347-354. [PubMed: 7714329]

[21]. Moazzami A, Tjen-A-Looi SC, Longhurst JC. Serotonergic projection from nucleus raphe pallidus to rostral ventrolateral medulla modulates cardiovascular reflex responses during acupuncture. J. Appl. Physiol. 2010 Epub ahead of print.

[22]. Paxinos, G.; Watson, C. The rat brain in stereotaxic coordinates. 4th edition. Academic Press; San Diego: 1998. 
[23]. Stornetta RL, Schreihofer AM, Guyenet PG. Preproenkephalin mRNA is expressed by C1 and non$\mathrm{C} 1$ barosensitive bulbospinal neurons in the rostral ventralateral medulla of the rat. J. Comp. Neurol 2001;435:111-126. [PubMed: 11370014]

[24]. Tjen-A-Looi SC, Li P, Longhurst JC. Role of medullary GABA, opioids, and nociceptin in prolonged inhibition of cardiovascular sympathoexcitatory reflexes during electroacupuncture in cats. Am. J. Physiol 2007;293:H3627-H3635.

[25]. Tjen-A-Looi SC, Li P, Longhurst JC. Prolonged inhibition of rostral ventral lateral medullary premotor sympathetic neuron by electroacupuncture in cats. Auton. Neurosci 2003;106(2):119131. [PubMed: 12878081]

[26]. Tjen-A-Looi SC, Li P, Longhurst JC. Medullary substrate and differential cardiovascular response during stimulation of specific acupoints. Am. J. Physiol 2004;287:R852-R862.

[27]. Tjen-A-Looi SC, Li P, Longhurst JC. Midbrain vIPAG inhibits rVLM cardiovascular sympathoexcitatory responses during acupuncture. Am. J. Physiol 2006;209:H2543-H2553.

[28]. Yao T, Andersson S, Thoren P. Long-lasting cardiovascular depression induced by acupuncturelike stimulation of the sciatic nerve in unanesthetized spontaneously hypertensive rats. Brain Res 1982;240:77-85. [PubMed: 7201339]

[29]. Yao T, Andersson S, Thoren P. Long-lasting cardiovascular depressor response following sciatic stimulation in spontaneously hypertensive rats. Evidence for the involvement of central endorphin and serotonin systems. Brain Res 1982;244:295-303. [PubMed: 6288187]

[30]. Zhou W, Fu L-W, Tjen-A-Looi SC, Li P, Longhurst JC. Afferent mechanisms underlying stimulation modality-related modulation of acupuncture-related cardiovascular responses. J. Appl. Physiol 2005;98:872-880. [PubMed: 15531558] 


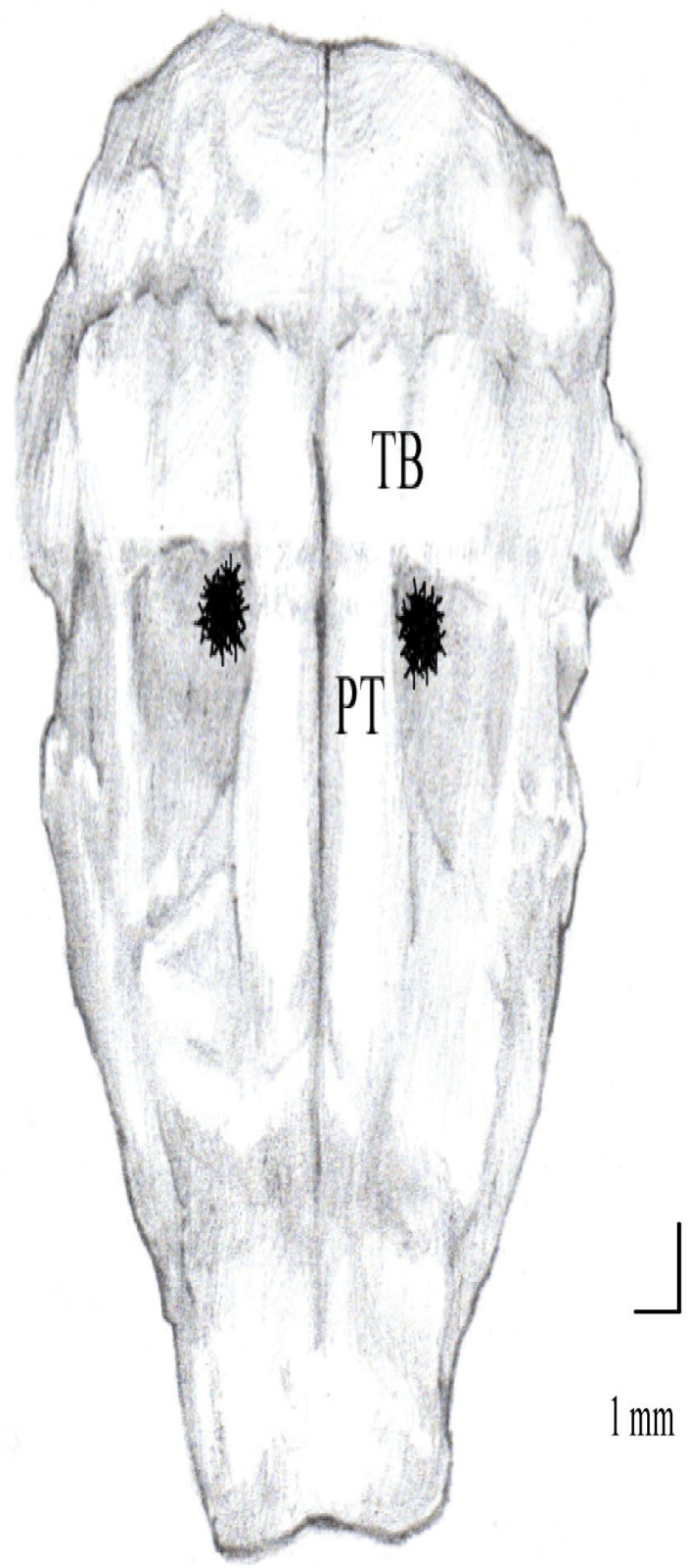




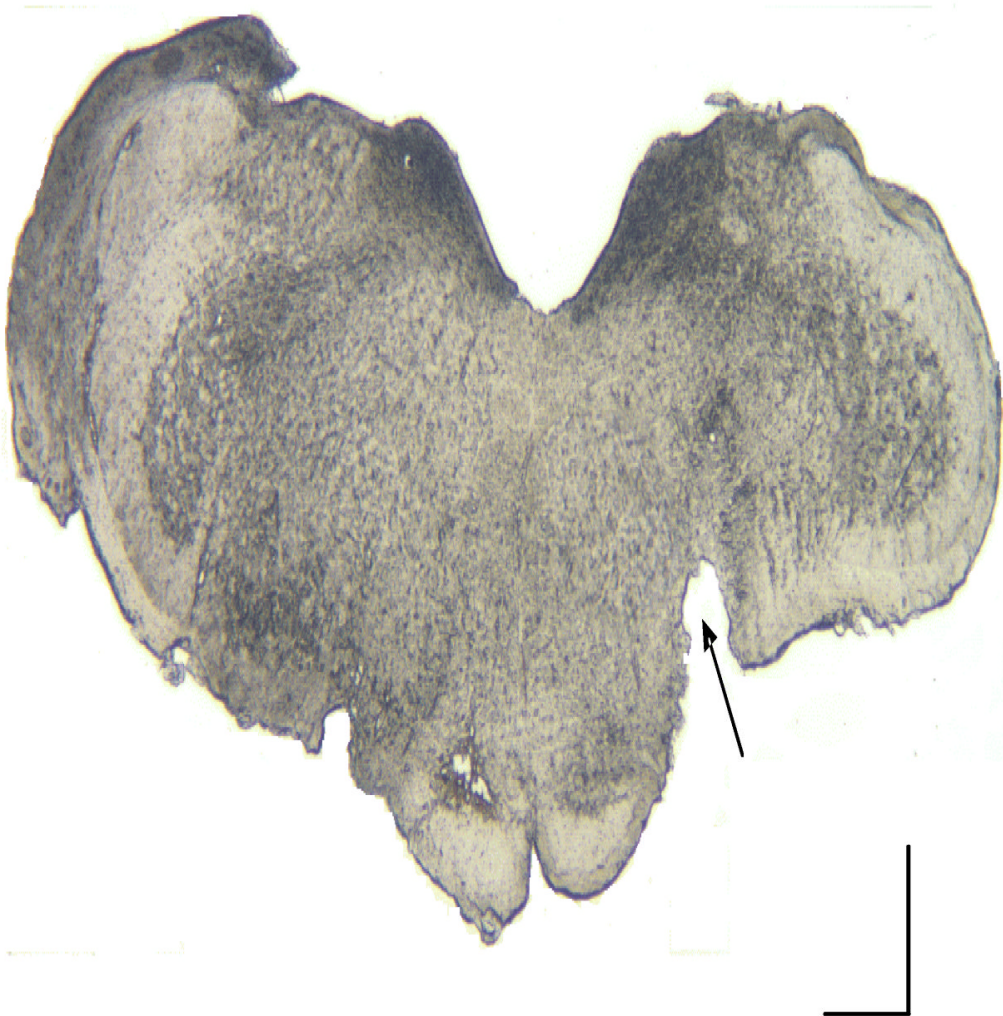

$1 \mathrm{~mm}$

Fig 1.

A: ventral view of the brain stem of the rat in which locations of all punch sites in the rVLM are plotted as shown by asterisks. B: punch biopsy (arrow) taken from rVLM region. TB, trapezoid body; PT, pyramidal tract. 


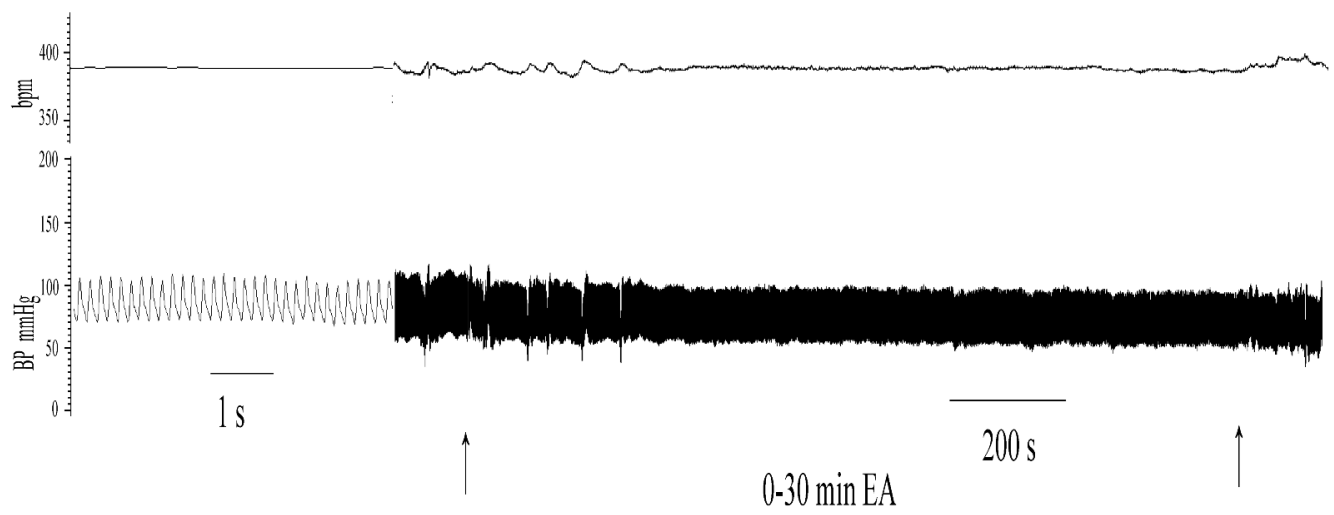

Fig.2.

The monitoring of blood pressure and heart rate of one rat 20 min following EA. 


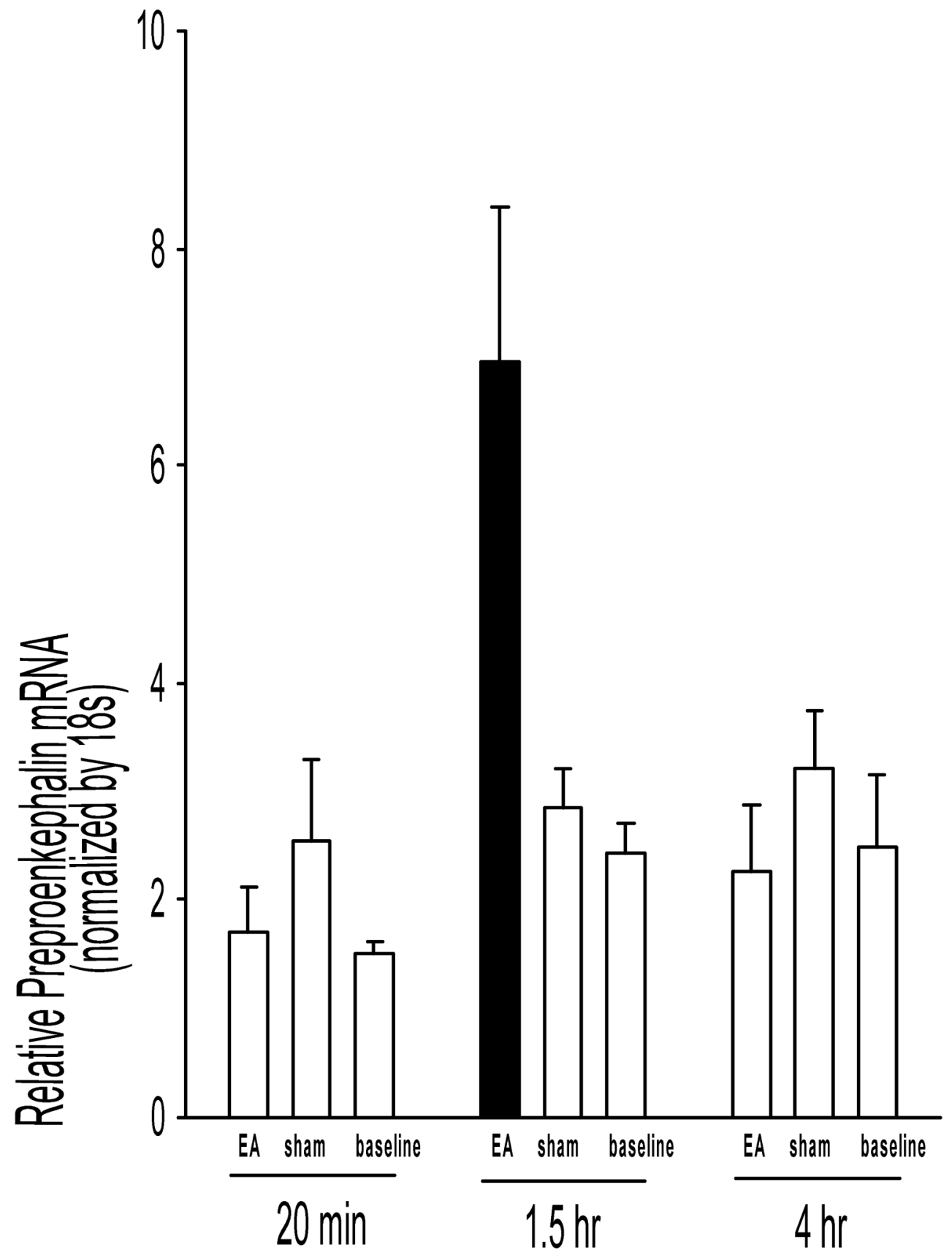

Fig 3.

Relative preproenkephalin mRNA levels. $n=6$ in all EA groups and $4 \mathrm{~h}$ sham group. $\mathrm{n}=5$ in sham and baseline of $1.5 \mathrm{hr}$ groups. $\mathrm{n}=4$ in sham and baseline of $20 \mathrm{~min}$ groups, and $4 \mathrm{~h}$ baseline group. 